\title{
DISTRIBUTION CHARACTERISTICS AND STABILITY OF SOIL AGGREGATES AS COMPOUNDED BY SOFT ROCK AND SAND UNDER DIFFERENT PLANTING YEARS OF CORN IN MU US SANDY LAND IN CHINA
}

\author{
Zhang Haiou $^{1,2,3 *}$, Guo ZheN ${ }^{1,2}$, Shi Chendi ${ }^{1,2,3}$ ANd Li Juan ${ }^{1,2,3}$ \\ Institute of Land Engineering and Technology, Shaanxi Provincial Land Engineering \\ Construction Group Co. Ltd., Xi'an 710021, Shaanxi Province, China
}

Keywords: Sandy soil, Soft rock, Corn, WSA, MWD, Soil structural stability

\begin{abstract}
Field plot experiments of compound soil mixing with soft rock and sand with ratios of $1: 1,1: 2$ and 1 : 5 during 2010-2018 years of corn cultivation in Mu Us Sandy Land in china., was carried out to observe the change characteristics of composition, distribution and mean weight diameter (MWD) of compound soil water stable aggregate (WSA) under different corn planting years. The results showed that with the increase of planting years, the content of WSA in composite soils of three portions with a particle size of $<0.25 \mathrm{~mm}$ gradually decreased, and WSA with a particle size of $>0.25 \mathrm{~mm}$ showed a continuous increasing trend. The WSA with a particle size of $0.25-0.5 \mathrm{~mm}$ accounted high for the maximum ratio, which plays an important role in the agglomeration of the compound soil. After 9 years of planting, the MWD of $1: 1,1: 2$ and $1: 5$ compound soil WSA increased by $1.13,1.85$ and 1.58 times, respectively, and t 1:2 compound soil WSA with particle size $>0.25 \mathrm{~mm}$ and MWD increase at a faster rate, which lead to a higher soil agglomeration and stability. The interaction between the mixture ratio of soft rock to sand and the planting years of corn has a significant impact on the formation and stability of WSA in the compound soil. With the increase of planting years of corn, the agglomeration effect of compound soil in different proportions was found to enhance, and the development of soil structure improve continuously.
\end{abstract}

\section{Introduction}

The amount particle size distribution and stability of soil aggregates are important indicators for the good development of soil structure (Das et al. 2014), especially the content of WSA has a significant impact on the physical, chemical, and biological properties of the soil (Hartley et al. 2016, Qu et al. 2019), which is crucial to retain water and fertilizer, coordinate soil water, fertilizer and air heat for crop growth. It is also the basic condition for crop growth, development, high yield and stable yield (Wang et al. 2014, Chaplot and Cooper 2015). Therefore, the composition and stability of soil WSA can be used to measure the degree of soil structural development and sustainable utilization (Mao et al. 2018, Li et al. 2019). The MWD is a common method to evaluate the characteristics and stability of soil aggregates. The larger the MWD value the higher the degree of soil agglomeration. The more stable soil structure, the better the soil development status (Darapuneni et al. 2021).

As two different materials, soft rock and sand in the Mu Us sandy land, Han et al. (2012) found that the two have complementary characteristics, and they were combined to form a reconstituted soil. The compound soil of soft rock and sand has the basic physical and chemical

*Author for correspondence: <academic_our@163.com>, <?244254409@qq.com>. ${ }^{1}$ Shaanxi Provincial Land Engineering Construction Group Co. Ltd., Xi'an 710075, China. ${ }^{2}$ Key Laboratory of Degraded and Unused Land Consolidation Engineering, the Ministry of Natural Resources of China, Xi' an 710021, China. ${ }^{3}$ Shaanxi Provincial Land Consolidation Engineering Technology Research Center, Xi' an 710075, China. 
properties of agricultural production. In the process of agricultural utilization, there are not only material accumulation and dynamic processes that promote soil agglomeration, but also dispersion risks and mechanisms. She et al. (2014) pointed out that the addition of soft rock can effectively improve the water and fertilizer retention capacity of aeolian sandy soil, and reduce the nutrient loss and water infiltration rate of aeolian sandy soil. Sun and Han (2018) found through moisture model analysis that the addition of soft rock can effectively improve the hydraulic parameters of aeolian sandy soil, which can significantly increase crop yields. Li et al. (2017) pointed out that the optimal combination ratio of soft rock and sand under the guidance of sand fixation is $1: 1 \sim$ $1: 5$, which has the strongest water retention and water holding performance. Previous studies were mostly based on the aspects of compound soil nutrients and water, but there are no reports on long-term soil structure studies. Therefore, it is necessary to carry out a series of studies on the agglomeration process and state of compounded soils, which will help to understand the structural development status and quality change trend of the newly created compound soil. Thus this study was aimed to analyze the composition, distribution and MWD of the three proportions of compound soil WSA under different planting years to characterize the stability of the soil WSA and the development of the soil structure. This finding will provide a theoretical basis for the scientific value and effect of using soft rock to improve aeolian sandy soil in the Mu Us Sandy Land.

\section{Materials and Methods}

The experimental area is located in Yuyang District, Yulin City, Mu Us Sandy Land. There is a big difference in temperature between winter and summer in this area. The average temperature in winter (January) is $-9.5 \sim-12^{\circ} \mathrm{C}$, and the average temperature in summer (July) is $24 \pm 2^{\circ} \mathrm{C}$. The rainfall during the year is almost concentrated in autumn (especially in August), which is about 60 to $75 \%$ of the annual precipitation. The inter-annual precipitation shows a significant difference, that is, the wet year is 2 to 4 times the precipitation of the dry year. The area has sufficient sunlight and shallow groundwater burial, which can meet the irrigation and growth of the local main crop corn. The experimental area is mainly distributed in aeolian sand soil and soft rock, which are alternately distributed. The sand particles are in a state of dispersion without agglomeration, with poor structure, loose soil, and poor water retention. There are abundant secondary clay minerals in soft rock, which can promote soil agglomeration and has good water holding capacity.

The field plot experiment for the compound soil of soft rock and sand was established in 2010 , and three repeated experiments were set up with the volume mixing ratio of soft rock and sand at $1: 1,1: 2$, and $1: 5$. Each plot experiment is $12 \mathrm{~m}$ long $\times 5 \mathrm{~m}$ wide. A total of 9 plots was set up to carry out long-term monitoring experiments on the quality of compound soil. According to the experimental design, the surface layer $(0 \sim 30 \mathrm{~cm})$ of aeolian sandy soil in the study area was covered with the compound soil in the ratio of $1: 1,1: 2,1: 5$ volumetric ratio of soft rock to sand. Then the two materials were thoroughly mixed by mechanical raking. Spring corn, the main local agricultural crop, is sown at early May each year. Compound fertilizer $(90 \mathrm{~kg} \mathrm{~N} / \mathrm{ha}, 40 \mathrm{~kg}$ $\mathrm{P} / \mathrm{ha}, 75 \mathrm{~kg} \mathrm{~K} / \mathrm{ha}$ ) was applied 1-2 days before planting, and urea was applied at $187 \mathrm{~kg} \mathrm{~N} / \mathrm{ha}$ once at the jointing stage of corn.

The experiment adopted the "S" sampling method after the corn harvest every year (Bao 2000). The soil aggregates were collected using aluminum boxes to get the undisturbed soil samples of the $0-20 \mathrm{~cm}$ surface soil under each treatment. Soils were collected from three points for each treatment, sealed and brought to the laboratory. The composition of WSA was determined by the wet sieve method (Zhao et al. 2013, David and María 2019). The $50 \mathrm{~g}$ of air-dried soil samples were mixed and the WSA content of each particle size of $>2,2-1,1-0.5,0.5-0.25$ and < 
$0.25 \mathrm{~mm}$ was determined using an agglomerate analyzer. Due to the unstable structure of the compound soil, the test method was slightly modified, which was set at 25 times/min and shook for $3 \mathrm{~min}$. Finally, the aggregate soil samples with different particle sizes on the sieve were placed in an aluminum box and dried $\left(105^{\circ} \mathrm{C}\right)$ to calculate the content of $>0.25 \mathrm{~mm}$ WSA.

The parameters of $>0.25 \mathrm{~mm}$ particle size WSA and MWD were used to measure the stability of aggregates (Zhou et al. 2020), and the calculation formula is as follows:

$$
\begin{aligned}
& \text { WSAC }=\sum_{i=1}^{n}(\mathrm{~W}) \\
& \mathrm{MW}=\sum_{\mathrm{i}=1}^{\mathrm{n}}\left(\overline{\mathrm{X}_{\mathrm{i}}} \times \mathrm{W}\right)
\end{aligned}
$$

Where, $W_{i}$ represents the content of agglomerates in the i-th particle size $(\mathrm{g}) ; X_{i}$ represents the MWD of the agglomerates in the i-th particle size (mm).

\section{Results and Discussion}

Before planting, $<0.25 \mathrm{~mm}$ WSA in the three proportions of compound soil accounted for the largest proportion (Table 1), with a range of 84.2 to $86.3 \%$. With the development of the experiment, the content of $<0.25 \mathrm{~mm}$ WSA in the $1: 1,1: 2$ and $1: 5$ compound soils decreased significantly, compared with before planting, the content decreased by 53.9, 67.9 and $60.7 \%$ after nine years of planting, with a range of 33.6 to $38.8 \%$.

Table 1. Composition of WSA in compound soil under different planting years of corn.

\begin{tabular}{lcccccc}
\hline \multirow{2}{*}{$\begin{array}{l}\text { Soft rock: } \\
\text { sand }\end{array}$} & Years & \multicolumn{5}{c}{ Percentage of WSA $(\%)$} \\
\cline { 2 - 6 } & & $>2 \mathrm{~mm}$ & $2-1 \mathrm{~mm}$ & $1-0.5 \mathrm{~mm}$ & $0.5-0.25 \mathrm{~mm}$ & $<0.25 \mathrm{~mm}$ \\
\hline $1: 1$ & 0 & $1.4 \pm 0.07 \mathrm{~d}$ & $2.1 \pm 0.11 \mathrm{~d}$ & $2.7 \pm 0.08 \mathrm{e}$ & $9.6 \pm 0.42 \mathrm{e}$ & $84.2 \pm 9.71 \mathrm{a}$ \\
& 1 & $1.9 \pm 0.12 \mathrm{~d}$ & $3.3 \pm 0.12 \mathrm{~d}$ & $3.4 \pm 0.27 \mathrm{~d}$ & $14.1 \pm 0.54 \mathrm{~d}$ & $77.3 \pm 7.94 \mathrm{ba}$ \\
& 3 & $3.2 \pm 0.30 \mathrm{c}$ & $4.7 \pm 0.23 \mathrm{~cd}$ & $6.5 \pm 0.34 \mathrm{c}$ & $18.9 \pm 1.26 \mathrm{c}$ & $66.7 \pm 5.35 \mathrm{~b}$ \\
& 5 & $4.8 \pm 0.44 \mathrm{~b}$ & $6.4 \pm 0.49 \mathrm{~b}$ & $9.9 \pm 0.52 \mathrm{~b}$ & $26.1 \pm 2.73 \mathrm{~b}$ & $52.8 \pm 7.48 \mathrm{~b}$ \\
& 7 & $6.1 \pm 0.61 \mathrm{a}$ & $8.2 \pm 0.47 \mathrm{a}$ & $10.4 \pm 1.29 \mathrm{a}$ & $32.6 \pm 1.96 \mathrm{a}$ & $42.7 \pm 5.72 \mathrm{c}$ \\
& 9 & $6.9 \pm 0.35 \mathrm{a}$ & $9.3 \pm 0.61 \mathrm{a}$ & $9.6 \pm 0.77 \mathrm{a}$ & $35.4 \pm 3.19 \mathrm{a}$ & $38.8 \pm 3.55 \mathrm{c}$ \\
\hline $1: 2$ & 0 & $1.1 \pm 0.15 \mathrm{~d}$ & $1.9 \pm 0.05 \mathrm{e}$ & $3.2 \pm 0.27 \mathrm{e}$ & $7.5 \pm 1.07 \mathrm{e}$ & $86.3 \pm 7.07 \mathrm{a}$ \\
& 1 & $1.7 \pm 0.31 \mathrm{~d}$ & $3.5 \pm 0.17 \mathrm{~d}$ & $3.8 \pm 0.31 \mathrm{e}$ & $12.1 \pm 0.63 \mathrm{~d}$ & $78.9 \pm 6.74 \mathrm{a}$ \\
& 3 & $3.9 \pm 0.47 \mathrm{c}$ & $5.2 \pm 0.39 \mathrm{c}$ & $4.3 \pm 0.44 \mathrm{de}$ & $17.1 \pm 1.82 \mathrm{c}$ & $69.5 \pm 10.16 \mathrm{~b}$ \\
& 5 & $5.4 \pm 0.43 \mathrm{c}$ & $8.1 \pm 0.42 \mathrm{~b}$ & $7.4 \pm 0.62 \mathrm{c}$ & $23.6 \pm 1.41 \mathrm{~b}$ & $55.5 \pm 2.75 \mathrm{c}$ \\
& 7 & $8.5 \pm 0.56 \mathrm{~b}$ & $12.6 \pm 0.72 \mathrm{a}$ & $10.3 \pm 1.35 \mathrm{~b}$ & $36.8 \pm 3.17 \mathrm{a}$ & $31.8 \pm 4.49 \mathrm{~d}$ \\
& 9 & $10.1 \pm 0.37 \mathrm{a}$ & $13.4 \pm 1.68 \mathrm{a}$ & $11.6 \pm 1.16 \mathrm{a}$ & $37.2 \pm 2.35 \mathrm{a}$ & $27.7 \pm 2.87 \mathrm{e}$ \\
\hline 1.5 & 0 & $0.8 \pm 0.08 \mathrm{~d}$ & $1.2 \pm 0.07 \mathrm{e}$ & $4.3 \pm 0.63 \mathrm{~cd}$ & $8.1 \pm 2.51 \mathrm{f}$ & $85.6 \pm 5.26 \mathrm{a}$ \\
& 1 & $1.4 \pm 0.13 \mathrm{~d}$ & $2.9 \pm 0.25 \mathrm{~d}$ & $4.7 \pm 0.45 \mathrm{c}$ & $11.2 \pm 1.29 \mathrm{e}$ & $79.8 \pm 6.87 \mathrm{~b}$ \\
& 3 & $2.8 \pm 0.19 \mathrm{c}$ & $4.4 \pm 0.61 \mathrm{c}$ & $3.3 \pm 0.59 \mathrm{~d}$ & $18.0 \pm 0.83 \mathrm{~d}$ & $71.5 \pm 5.09 \mathrm{c}$ \\
& 5 & $3.7 \pm 0.22 \mathrm{c}$ & $6.3 \pm 0.36 \mathrm{~b}$ & $5.2 \pm 0.37 \mathrm{c}$ & $25.4 \pm 1.75 \mathrm{c}$ & $59.4 \pm 4.72 \mathrm{~d}$ \\
& 7 & $5.9 \pm 0.47 \mathrm{~b}$ & $10.7 \pm 0.82 \mathrm{a}$ & $7.5 \pm 0.94 \mathrm{~b}$ & $31.4 \pm 2.24 \mathrm{~b}$ & $44.5 \pm 2.45 \mathrm{e}$ \\
& 9 & $7.8 \pm 0.39 \mathrm{a}$ & $11.1 \pm 0.79 \mathrm{a}$ & $12.3 \pm 1.15 \mathrm{a}$ & $35.2 \pm 3.48 \mathrm{a}$ & $33.6 \pm 3.58 \mathrm{f}$ \\
\hline
\end{tabular}


Correspondingly, the content of $>0.25 \mathrm{~mm}$ WSA in the 1:1, 1:2, and 1:5 compound soils showed an overall increasing trend, and the content of WSA with a particle size of $0.25-0.5 \mathrm{~mm}$ increased by $2.69,3.96,3.34$ times, respectively, the content of WSA with a particle size of 1-0.5 $\mathrm{mm}$ increased by $2.56,2.63$ and 1.86 times, respectively; the content of WSA with a particle size of $2-1 \mathrm{~mm}$ increased by $3.43,6.05$ and 8.25 times, respectively; the content of $>2 \mathrm{~mm}$ WSA increased by $3.93,8.18$ and 8.75 times, respectively, and the soil structure continued to develop in the direction of agglomeration.

Results showed that the planting years has a significant impact on the newly-created soil aggregates. With the development of the experiment, the content of aggregates with a particle size of $<0.25 \mathrm{~mm}$ gradually decreased, and the content of aggregates with a particle size of $>0.25 \mathrm{~mm}$ increased, and the compound soil showed continuous agglomeration trends. This is mainly because the interaction between the planting years of corn and the mixing ratio of soft rock and sand promoted the formation of WSA in the compound soil, and improved the quality of the aggregates to a certain extent, especially enhanced the agglomeration effect of $1: 2$ and 1:5 compound soil.

Before planting, the content of WSA with a particle size of $0.25-2 \mathrm{~mm}$ was $1: 1>1: 5>1$ : 2 , and the range of change was $14.4 \sim 12.6 \%$, and there was no significant difference among different proportions $(\mathrm{p}>0.05)$ (Fig. 1). With the development of the experiment, the composition of WSA in the three proportions of compound soil gradually changed from $<0.25 \mathrm{~mm}$ particle size to mainly $0.25-2 \mathrm{~mm}$ fine and large aggregates. Compared with before planting, after nine years of planting, the WSA content of 0.25-2 mm particle size in 1:1, 1:2 and 1:5 compound soil increased by $2.77,3.94$ and 3.31 times, respectively. The aggregate content in this particle size range was $1: 2>1: 5>1: 1$, with a range of $54.3 \sim 62.2 \%$, and there was a significant difference among different proportions $(\mathrm{p}<0.05)$.

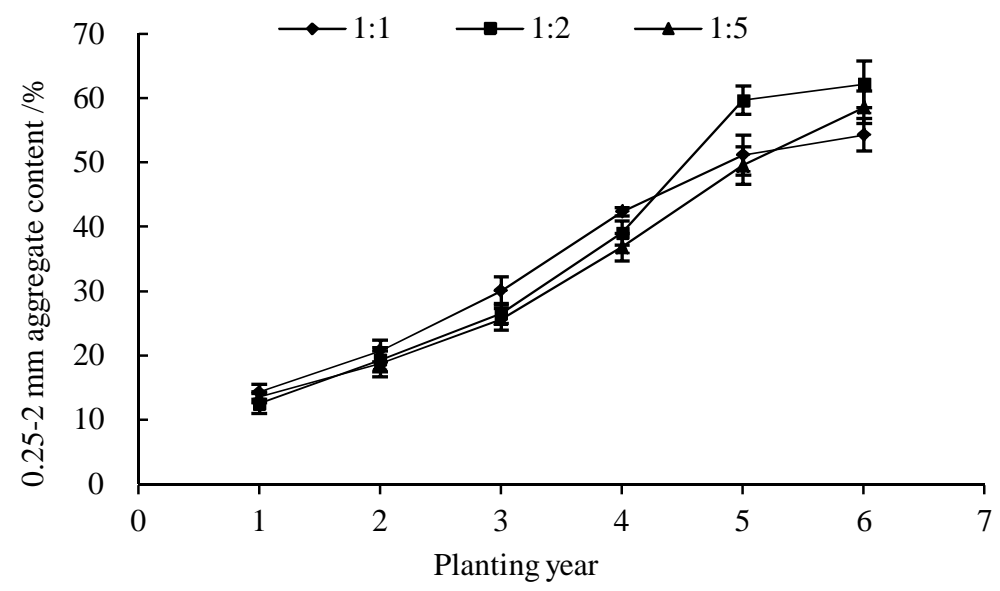

Fig. 1. Interannual variation of $0.25-2 \mathrm{~mm}$ WSA in different proportions of compound soil.

Before planting, the content of $>2 \mathrm{~mm}$ WSA in the three proportions of compound soil was $1: 1>1: 2>1: 5$ (Fig. 2), and the variation range was $0.8 \sim 1.4 \%$, which is relatively small, and there was no significant difference among all proportions $(\mathrm{p}>0.05)$. With the development of the experiment, the content of $>2 \mathrm{~mm}$ WSA in $1: 1,1: 2$ and $1: 5$ compound soils showed a continuous increase. After 9 years of planting, aggregate content increased by $3.93,8.18$ and 8.75 times and the mass percentage of aggregates varied from 6.9 to $10.1 \%$. 


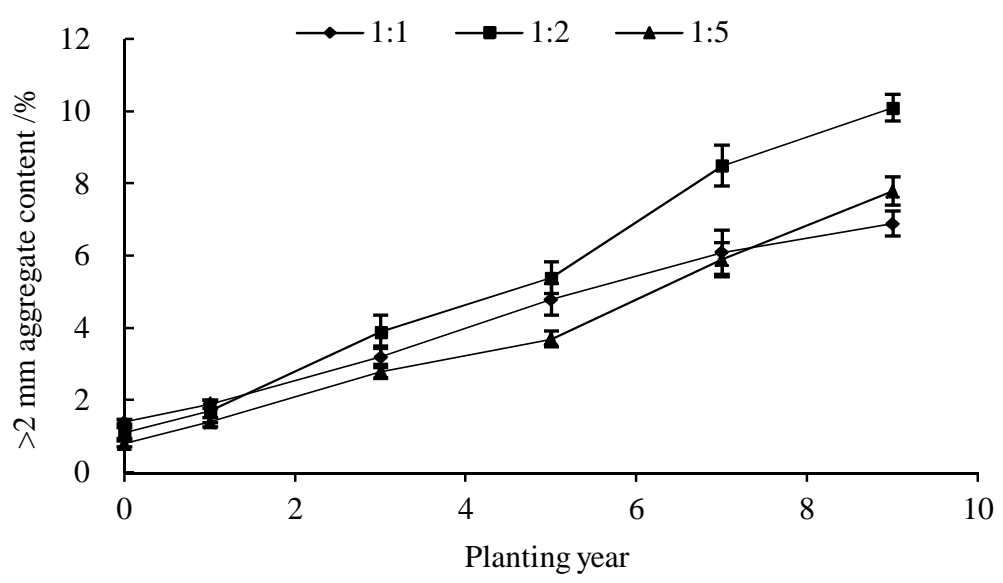

Fig. 2. Interannual variation of $>2 \mathrm{~mm}$ WSA in different proportions of compound soil.

With the increase of corn planting years, the content of WSA with a particle size of $0.25-0.5$ $\mathrm{mm}$ accounted for the largest proportion, which is the main component of aggregates with a particle size of $>0.25 \mathrm{~mm}$. This might be due to the root system and its exudates which can consolidate and aggregate soil particles to form a stable aggregate structure. Crop planting has changed the material basis of compound soil agglomeration (Meng et al. 2014), making the $<0.25$ $\mathrm{mm}$ micro-aggregates transform into $0.25-0.5 \mathrm{~mm}$ small and medium-sized aggregates, and the compound soil agglomeration is enhanced, and there is a trend of further agglomeration.

With the increase of planting years, the MWD of compound soil WSA with the three proportions showed an increasing trend (Fig. 3). The MWD of 1:1 compound soil WSA showed a slow increasing trend, and there were significant differences in MWD of 3, 5 and 7 years after planting ( $\mathrm{p}<0.05)$, and MWD gradually stabilized among different years after planting 7 years ( $p>0.05$ ). The $1: 2$ compound soil MWD before planting and 1 year after planting was not significantly different, after 3 years of planting, the MWD showed a significant increasing trend, and there were significant differences in MWD values between 3, 5, 7 and 9 years $(\mathrm{p}<0.05)$. There was no significant difference in MWD value of $1: 5$ compound soil before planting, 1 year, 3 years, and 5 years $(\mathrm{p}>0.05)$, but MWD value increased significantly after 5 years of planting and reached the maximum value after 9 years of planting. Compared with before planting, the MWD value of $1: 1,1: 2$ and 1:5 compound soil increased by 1.13, 1.85 and 1.58 times after 9 years of planting, of which $1: 2$ and 1:5 compound soil increased rate significantly higher than the 1:1 compound ratio.

MWD is an important indicator for evaluating the stability of soil aggregates (Liu et al. 2014). The interaction between soil parent material and corn planting years affects the formation and stability of compound soil aggregates. According to related research (Luo et al. 2013, Wang et al. 2017, Sun and Han 2018), the interaction of corn growth characteristics and the mixing ratio of soft rock and sand makes the clay and organic matter content of $1: 2$ compound soil higher than $1: 1$ and $1: 5$ compound ratio. However, the content of soil organic matter and clay directly affects the aggregation and cementation of soil particles. The higher the content of soil clay and organic matter, the stronger the soil agglomeration and the higher the soil stability (An et al. 2010). 


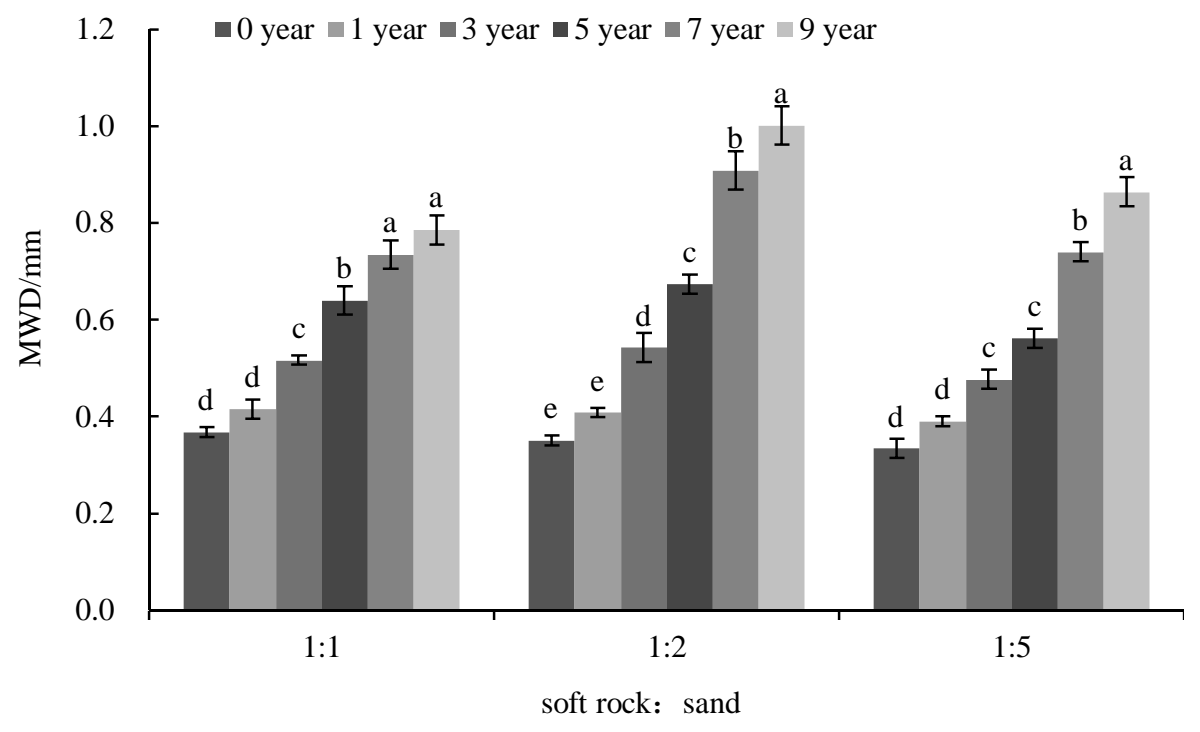

Fig. 3. MWD variation characteristics of compound soil WSA in different proportions.

With the development of the experiment, the WSA and MWD of $>0.25 \mathrm{~mm}$ particle size in the three proportions of compound soil showed a continuous increasing trend. After 9 years of planting, the main component of aggregates with a particle size of $>0.25 \mathrm{~mm}$ was $0.25-0.5 \mathrm{~mm}$, and the soil agglomeration effect of $1: 2$ and $1: 5$ compound soil was significantly higher than that of $1: 1$ compound soil. With the increase of corn planting years, the agglomeration effect of compound soil with the three proportions is increased, and the stability of the aggregates is continuously improved. The soil is in a trend of continuous maturation and sustainable development, and it does not need to be compounded again after many years.

\section{Acknowledgements}

This study was financially supported by Shaanxi Provincial Natural Science Basic Research Program (2021JZ-57), funded by Technology Innovation Center for Land Engineering and Human Settlements, Shaanxi Land Engineering Construction Group Co., Ltd. and Xi'an Jiaotong University (2021WHZ0087), Fund Project of Shaanxi Key Laboratory of Land Consolidation (2018-JC18, 2019-JC07, 2019-JC08) and Shaanxi Provincial Land Engineering Construction Group internal research project (DJNY2021-25).

\section{References}

An SS, Mentler A, Mayer H and Blum WEH 2010. Soil aggregation, aggregate stability, organic carbon and nitrogen in different soil aggregate fractions under forest and shrub vegetation on the Loess Plateau, China. Catena 81: 226-233.

Bao SD 2000. The soil agricultural analysis. Beijing: China Agriculture Press, 30-172.

Chaplot V and Cooper M 2015. Soil aggregate stability to predict organic carbon outputs from soils. Geoderma 243: 205-213.

Chen GP, Gao ZY, Zu LH, Tang LL, Yang T, Feng XM, Zhao TJ and Shi FC 2017. Soil aggregate characteristics and stability of soil carbon stocks in a Pinus tabulaeformis plantation. New Forests 48 : 837-853. 
Darapuneni MK, Idowu OJ, Sarihan B and Dubois DW 2021. Growth characteristics of summer cover crop grasses and their relation to soil aggregate stability and wind erosion control in arid southwest. Appl. Engin. Agricul. 37: 11-23.

Das B, Chakraborty D, Singh VK, Aggarwal P, Singh R, Dwivedi BS and Mishra RP 2014. Effect of integrated nutrient management practice on soil aggregate properties, its stability and aggregateassociated carbon content in an intensive rice-wheat system. Soil Tillage Res. 36: 9-18.

David MF and María VL 2019. Determination of soil aggregate porosity using the modified water saturation method. Pedosphere 29: 794-800.

Hartley W, Riby P and Waterson J 2016. Effects of three different biochars on aggregate stability, organic carbon mobility and micronutrient bioavailability. J. Environ. Manag. 181: 770-778.

Han JC, Xie JC and Zhang Y 2012) Potential role of feldspathic sandstone as a natural water retaining agent in Mu Us Sandy Land, northwest China. Chinese Geograph. Sci. 22: 550-555.

Li W, Luo XS, Xiong X, Chen WL, Hao XL and Huang QY 2019. Soil aggregate stratification of ureolytic microbiota affects urease activity in an inceptisol. J. Agricul. Food Chem. 67: 11584-11590.

Li YR, Fan PC, Cao Z, Chen YF, Liu YS, Wang HY, Liu HH and Ma F 2017. Sand-fixation effect and micromechanism of remixing soil by Pisha Sandstone and sand in the Mu Us Sandy Land, China. J. Desert Res. 37: 421-430.

Liu WL, Wu JG, Fu MJ, Liang YJ and Zhao XY 2014. Effect of different cultivation years on composition and stability of soil aggregate fractions in orchard. J. Soil Water Conserv. 28: 129-135.

Luo LT, Cheng J, Wang HY, Han JC, Hu YT and Ma ZH 2013. Nitrogen leaching characteristics in the compound soil of feldspathic sandstone and sand under corn conditions. J. Soil Water Conserv. 27: 5866.

Mao R, Ye S and Zhang X 2018. Soil-aggregate-associated organic carbon along vegetation zones in tidal salt marshes in the Liaohe Delta. Clean-Soil Air Water, 46: 1-7.

Meng Q, Sun Y, Zhao J, Zhou L, Ma X, Zhou M, Gao W and Wang G 2014. Distribution of carbon and nitrogen in water-stable aggregates and soil stability under long-term manure application in solonetzic soils of the Songnen plain, northeast China. J. Soils Sediments 14: 1041-1049.

Qu Q, Xu HW, Wu X, Meng M, Wang GL and Xue S 2019. Soil aggregate stability and its stoichiometric characteristics of robinia pseudoacacia forest in different vegetation zones on the Loess Plateau, China. Environ. Sci. 40: 2904-2911.

She XY, Zhang XC and Wei XR 2014. Improvement of water absorbing and holding capacities of sandy soil by appropriate amount of soft rock. Transactions of the Chinese Society of Agricultural Engineering 30: 115-123.

Sun ZH and Han JC 2018. Effect of soft rock amendment on soil hydraulic parameters and crop performance in Mu Us Sandy Land, China. Field Crops Res. 222: 85-93.

Wang L, Li J, Li J and Bai WX 2014. Effects of tillage rotation and fertilization on soil aggregates and organic carbon content in corn field in Weibei Highland. Chinese J. Appl. Ecol. 25: 759-768.

Wang HY, Han JC, Tong W, Cheng J and Zhang HO 2017. Analysis of water and nitrogen use efficiency for maize (Zea mays L.) grown on soft rock and sand compound soil. Journal of the Science of Food \& Agricul. 97: 2553-2560.

Zhao YM, Gao XF, Liu YN and Jiang HT 2013. Comparison of different pre-wetting strategies in wet aggregate stability determination. Bulletin of Soil and Water Conserv. 33: 138-143.

Zhou M, Liu CZ, Wang J, Meng QF, Yuan Y, Ma XF, Liu XB, Zhu YX, Ding GW and Zhang JZ 2020. Soil aggregates stability and storage of soil organic carbon respond to cropping systems on Black Soils of Northeast China. Sci. Rep. 10: 265.

(Manuscript received on 19 May, 2021; revised on 28 September, 2021) 